\title{
SISTEM PENDUKUNG KEPUTUSAN KENAIKAN JABATAN DENGAN METODE AHP-TOPSIS (STUDI KASUS: PT. MAKMUR CITRA ABADI)
}

\author{
Tiara Imas Ayu ${ }^{1}$, Rudy Ariyanto ${ }^{2}$,Yan Watequlis Syaifudin ${ }^{3}$ \\ ${ }^{1,2}$ Teknik Informatika, Teknologi Informasi, Politeknik Negeri Malang \\ 1.
}

\begin{abstract}
Abstrak
Selama ini kenaikan jabatan di PT. Makmur Citra Abadi masih dilakukan secara manual, sehingga tidak menutup kemungkinan jika pengambilan keputusan dilakukan secara subjektif dengan hanya melihat pada aspek tertentu saja. Disamping itu terdapat hambatan dalam penyeleksian mengenai pembobotan kriteria sehingga pengambil keputusan sulit menentukan bobot dalam bentuk angka. Melihat masalah tersebut, maka diperlukan sistem pendukung keputusan (SPK) yang dapat membantu memecahkan masalah tersebut. Sistem pendukung keputusan kenaikan jabatan diharapkan mampu mengatasi masalah tersebut dengan menyesuaikan bobot dan kriteria. Metode yang digunakan untuk membantu dan mendukung dalam pengambilan keputusan ini adalah metode Analytic Hierarchy Process (AHP) dan Technique Order Preference by Similarity To Ideal Solution (TOPSIS). Aplikasi ini dapat membuat proses penilaian dan pengambilan keputusan menjadi lebih mudah karena adanya dukungan dalam pengambilan keputusan. Selain itu seleksi kandidat yang dilakukan dengan aplikasi ini dapat memberikan hasil cukup akurat, hal ini terbukti dengan pengujian yang telah dilakukan dari perbandingan seleksi manual dan seleksi sistem dengan keakuratan $95 \%$.
\end{abstract}

Kata Kunci: Sistem Pendukung Keputusan, Kenaikan Jabatan, AHP-TOPSIS.

\section{Pendahuluan}

PT. Makmur Citra Abadi merupakan perusahaan yang bergerak di bidang trading keramik yang menjalankan perdagangan umum, ekspor, dan lokal. Terdapat banyak faktor yang mendukung kemajuan perusahaan, salah satunya adalah pegawai (sumber daya manusia) yang ada di dalamnya. Bagi perencanaan karir pegawai, kenaikan jabatan merupakan hal yang sangat penting karena berfungsi untuk meremajakan suatu posisi jabatan agar diduduki oleh seseorang yang mempunyai kriteriakriteria yang cocok untuk menempati jabatan yang diusulkan.

Selama ini kenaikan jabatan di PT. Makmur Citra Abadi masih dilakukan secara manual, yakni pihak personalia mengkasifikasikan pegawai menjadi kandidat-kandidat yang cocok untuk menempati suatu jabatan, setelah ditemukan kandidatnya, dilakukan proses wawancara untuk menentukan satu pegawai yang menempati jabatan tersebut, sehingga membutuhkan waktu yang lama dalam mendapatkan hasil rekomendasi pegawai. Serta tidak menutup kemungkinan jika pengambilan keputusan dilakukan secara subjektif. Untuk menghindari hal-hal tersebut, maka diperlukan sistem pendukung keputusan (SPK) yang dapat membantu memecahkan masalah tersebut. Sistem pendukung keputusan kenaikan jabatan diharapkan mampu mengatasi masalah tersebut dengan menyesuaikan kriteria dan bobot keputusan apa yang akan diambil.
Dengan melihat masalah diatas, maka metode Technique Order Preference by Similarity To Ideal Solution (TOPSIS) merupakan metode yang sesuai karena konsepnya yang sederhana, mudah dipahami, komputasi efisien dan memiliki kemampuan untuk menghitung banyak alternatif dan kriteria yang jumlahnya tak terhingga, dengan demikian metode ini akan digunakan dalam perhitungan alternatif. Namun, metode TOPSIS memiliki kekurangan yakni harus ada bobot yang ditetapkan dan dihitung terlebih dahulu, sedangkan pada kasus ini bobot belum ditentukan, oleh karena itu metode Analytical Hierarchy Process (AHP) dibutuhkan untuk perhitungan bobot, karena AHP membandingkan tingkat kepentingan tiap kriteria yang nantinya digunakan untuk menghasilkan bobot kriteria yang konsisten, selain itu AHP mempunyai kemampuan untuk memecahkan masalah dengan banyak kriteria. Metode ini dikenal fleksibel, dalam arti mampu mencangkup seluruh permasalahan dengan tujuan dan kriteria yang beragam,

Berdasarkan uraian di atas penulis ingin membuat sistem yang mampu memberikan kemudahan bagi perusahaan dengan mewujudkannya dalam tugas akhir dengan mengambil judul "Sistem Pendukung Keputusan Kenaikan Jabatan dengan Metode AHP-TOPSIS (Studi Kasus PT. Makmur Citra Abadi)". 


\section{Landasan Teori}

\subsection{Sistem Pendukung Keputusan}

Sistem Pendukung Keputusan (SPK) adalah sebuah sistem yang mampu memberikan kemampuan pemecahan masalah maupun kemampuan pengkomunikasian untuk masalah dengan kondisi semi terstruktur dan tak terstruktur. Sistem ini digunakan untuk membantu pengambilan keputusan dalam situasi semi terstruktur dan situasi yang tidak terstruktur, dimana tak seorangpun tahu secara pasti bagaimana keputusan seharusnya dibuat (Turban, 2001). Sistem Pendukung Keputusan adalah sebuah sistem yang memberikan kemudahan seorang pengambil keputusan dengan memberikan rekomendasi dalam keputusan yang akan diambilnya.

\subsection{Metode AHP}

Metode AHP dikembangakan oleh Dr. Thomas L. Saaty dari Wharton School of Bussiness pada tahun 1970-an untuk mengorganisasikan informasi dan judgement dalam memilih alternatif yang disukai (Marimin, 2004). Pada dasarnya proses pengambilan keputusan menggunakan metode AHP adalah memilih suatu alternatif. Peralatan utama AHP adalah sebuah hierarki fungsional dengan input utamanya persepsi manusia.

Penentuan nilai bobot kriteria dengan metode AHP di penelitian ini menggunakan perbandingan nilai yang diubah menjadi keterangan kalimat, sehingga dapat memudahkan penilai dalam menentukan perbandingan pada kriteria-kriteria yang ada. Penjelasan keterangan kalimat serta nilai dapat dilihat dari tabel berikut.

Tabel 1 Keterangan Penilaian AHP

\begin{tabular}{|c|l|}
\hline $\begin{array}{c}\text { Intensitas } \\
\text { Kepentingan }\end{array}$ & \multicolumn{1}{|c|}{ Keterangan } \\
\hline 1 & \begin{tabular}{|}
$|c|$ \\
Kedua elemen sama pentingnya
\end{tabular} \\
\hline 3 & $\begin{array}{l}\text { Elemen yang satu sedikit lebih } \\
\text { penting daripada elemen yang } \\
\text { lainnya }\end{array}$ \\
\hline 5 & $\begin{array}{l}\text { Elemen yang satu lebih penting } \\
\text { daripada yang lainnya }\end{array}$ \\
\hline 9 & $\begin{array}{l}\text { Satu elemen jelas lebih mutlak } \\
\text { penting daripada elemen lainnya }\end{array}$ \\
\hline $2,4,6,8$ & $\begin{array}{l}\text { Satu elemen mutlak penting } \\
\text { daripada elemen lainnya }\end{array}$ \\
\hline Kebalikan & $\begin{array}{l}\text { Nilai-nilai antara dua nilai } \\
\text { pertimbangan berdekatan }\end{array}$ \\
\hline $\begin{array}{l}\text { Jika aktifitas i mendapat satu } \\
\text { angka dibandingkan dengan } \\
\text { aktivitas j, maka i memiliki nilai } \\
\text { keblikannya dibandingkan dengan } \\
\mathrm{j}\end{array}$ \\
\hline Sumber : Saaty (1988)
\end{tabular}

Prosedur atau langkah-langkah dalam metode AHP meliputi (Kusrini, 2007):

a. Mengidentifikasi masalah dan menentukan solusi yang diinginkan, lalu menyusun hierarki dari permasalahan yang dihadapi.

b. Menentukan perbandingan berpasangan diisi menggunakan bilangan untuk merepresentasikan kepentingan relatif dari suatu elemen terhadap elemen yang lainnya.

c. Sintesis

Hal-hal yang dilakukan dalam langkah ini adalah

1) Menjumlahkan nilai-nilai dari setiap kolom pada matriks

2) Membagi setiap nilai dari kolom dengan total kolom yang bersangkutan untuk memperoleh normalisasi matriks.

3) Menjumlahkan nilai-nilai dari setiap baris dan membaginya dengan jumlah elemen untuk mendapatkan nilai rata-rata.

d. Mengukur Konsistensi

Dalam membuat keputusan, penting untuk mengetahui seberapa baik konsistensi yang ada karena kita tidak menginginkan keputusan berdasarkan pertimbangan dengan konsistensi yang rendah. Hal hal yang dilakukan dalam langkah ini adalah :

1). Mengkalikan nilai rata-rata dengan jumlah nilai-nilai dari setiap kolom pada matriks.

2). Jumlahkan hasil kali di atas, hasilnya disebut ( $\lambda$ ) maks.

e. Menghitung Consistency Index (CI), dengan rumus :

$$
\mathrm{CI}=\frac{\lambda_{\max }-n}{n-1}
$$

Dimana $\mathrm{n}=$ banyaknya elemen.

f. Menghitung Consistency Ratio (CR), dengan rumus:

$\mathrm{CR}=\frac{C I}{I R}$

$$
\begin{gathered}
\text { Dimana : } \quad \mathrm{CR}=\text { Consistency Ratio } \\
\mathrm{CI}=\text { Consistency Indeks } \\
\mathrm{IR}=\text { Index Random Consistency }
\end{gathered}
$$

g. Memeriksa konsistensi hierarki. Jika nilainya lebih dari $10 \%$, maka penilaian data judgment harus diperbaiki. Namun jika rasio konsistensi (CI/IR) kurang atau sama dengan 0,1 maka hasil perhitungan bisa dinyatakan benar. Daftar Index Random Consistency (IR) bisa dilihat pada Tabel 2 di bawah ini. 
Tabel 2 Daftar Index Random Consistency

\begin{tabular}{|c|c|c|c|}
\hline $\begin{array}{c}\text { NILAI } \\
\text { MATRIKS }\end{array}$ & $\begin{array}{c}\text { NILAI } \\
\text { IR }\end{array}$ & $\begin{array}{c}\text { NILAI } \\
\text { MATRIKS }\end{array}$ & $\begin{array}{c}\text { NILA } \\
\text { I IR }\end{array}$ \\
\hline 1,2 & 0.00 & 9 & 1.45 \\
\hline 3 & 0.58 & 10 & 1.49 \\
\hline 4 & 0.90 & 11 & 1.51 \\
\hline 5 & 1.12 & 12 & 1.48 \\
\hline 6 & 1.24 & 13 & 1.56 \\
\hline 7 & 1.32 & 14 & 1.57 \\
\hline 8 & 1.41 & 15 & 1.59 \\
\hline
\end{tabular}

\subsection{Metode TOPSIS}

Pada dasarnya proses pengambilan keputusan adalah memilih suatu alternatif. TOPSIS didasarkan pada konsep dimana alternatif terpilih yang terbaik tidak hanya memiliki jarak terpendek dari solusi ideal positif, namun juga memiliki jarak terpanjang dari solusi ideal negatif (Kusumadewi, 2006). Menurut Hwang, Liang dan Yeh dalam (Kusumadewi, 2006), konsep ini banyak digunakan pada beberapa model Multi-Attribute Decision Making (MADM) untuk menyelesaikan masalah keputusan secara praktis. Hal ini disebabkan konsepnya sederhana, mudah dipahami, komputasi yang efisien dan memiliki kemampuan mengukur kinerja relatif dari alternatif-alternatif keputusan dalam bentuk sistematis yang sederhana.

Secara umum prosedur atau langkah-langkah dalam metode TOPSIS meliputi (Asep, 2012):

a. Membuat matriks keputusan yang ternormalisasi

b. Membuat matriks keputusan yang ternormalisasi terbobot

c. Menentukan matriks solusi ideal positif dan matriks solusi ideal negatif

d. Menentukan jarak antara nilai setiap alternatif dengan solusi ideal positif dan matriks solusi odeal negatif

e. Menentukan nilai prefensi untuk setiap alternatif

TOPSIS membutuhkan nilai kinerja setiap alternatif $A_{i}$ pada setiap kriteria $\mathrm{Cj}$ yang ternormalisasi, yaitu :

$$
r_{i j}=\frac{x_{i j}}{\sqrt{\sum_{i-1}^{m} x_{i j}^{2}}}
$$

Dengan $\mathrm{i}=1,2, \ldots, \mathrm{m} ;$ dan $\mathrm{j}=1,2, \ldots, \mathrm{n}$

Solusi ideal positif $A^{+}$dan solusi ideal negatif $A^{-}$dapat ditentukan berdasarkan rating bobot ternormalisasi $\left(y_{i j}\right)$ sebagai :

$$
\begin{array}{r}
y_{i j}=x_{i} r_{i j} ; \ldots \ldots \ldots \ldots \ldots \ldots \ldots \ldots . . . \ldots \\
\text { Dengan } \mathrm{i}=1,2, \ldots, \mathrm{m} ; \text { dan } \mathrm{j}=1,2, \ldots, \mathrm{n} \\
A^{+}=\left(y_{1}^{+}, y_{2}^{+}, \ldots, y_{n}^{+}\right)
\end{array}
$$

$$
\begin{aligned}
& A^{-}=\left(y_{1}^{-}, y_{2}^{-}, \ldots, y_{n}^{-}\right) \\
& \text {Dengan } \\
& y_{j}^{+}=\left\{\begin{array}{c}
\max _{\mathrm{i}} \mathrm{j}_{\mathrm{ij}} ; \mathrm{jika} \mathrm{j} \text { adalah atribut keuntungan } \\
\min _{\mathrm{i}} \mathrm{j}_{\mathrm{ij}} ; \mathrm{jika} \mathrm{j} \text { adalah atribut biaya }
\end{array}\right. \\
& y_{j}^{-}=\left\{\begin{array}{c}
\min _{\mathrm{i}} \mathrm{j}_{\mathrm{ij}} ; \mathrm{jika} \mathrm{j} \text { adalah atribut keuntungan } \\
\max _{\mathrm{i}} \mathrm{j}_{\mathrm{ij}} ; \mathrm{jika} \mathrm{j} \text { adalah atribut biaya }
\end{array}\right. \\
& \mathrm{j}=1,2, \ldots, \mathrm{n}
\end{aligned}
$$

Jarak antara alternatif $A_{i}$ dengan solusi ideal positif dirumuskan sebagai:

$$
\begin{aligned}
& D_{i}^{+}=\sqrt{\sum_{j=1}^{n}\left(y_{i}^{+}-y_{i j}\right)^{2}} \\
& \text { Dengan } \mathrm{i}=1,2, \ldots, \mathrm{m}
\end{aligned}
$$

Jarak antara alternatif $A_{i}$ dengan solusi ideal negatif dirumuskan sebagai:

$$
\begin{aligned}
& D_{i}^{-}=\sqrt{\sum_{j=1}^{n}\left(y_{i j}-y_{i}^{-}\right)^{2}} \\
& \text { Dengan } \mathrm{i}=1,2, \ldots, \mathrm{m}
\end{aligned}
$$

Nilai prefensi untuk setiap alternatif $\left(V_{i}\right)$ diberikan sebagai:

$$
\begin{aligned}
& V_{i} \frac{D_{i}^{-}}{D_{i}^{-}+D_{i}^{+}} \quad \ldots \ldots \ldots \ldots . . . \\
& \text { Dengan } \mathrm{i}=1,2, \ldots, \mathrm{m}
\end{aligned}
$$

Nilai $V_{i}$ yang lebih besar menunjukkan bahwa alternatif $A_{i}$ lebih dipilih.

\subsection{Kenaikan Jabatan PT. Makmur Citra Abadi}

Kenaikan jabatan merupakan hal yang sangat penting karena berfungsi untuk meremajakan suatu posisi jabatan agar diduduki oleh seseorang yang mempunyai kriteria-kriteria yang cocok untuk menempati jabatan yang diusulkan. Dalam kenaikan jabatan ini kandidat diseleksi berdasarkan kriteriakriteria yang telah ditentukan. Setiap jabatan yang akan diisi oleh kandidat mempunyai bobot disesuaikan dengan kebutuhan masing-masing jabatan. Kriteria yang digunakan dalam kenaikan jabatan dalam penelitian ini ditunjukan pada tabel berikut.

Tabel 3 Data Kriteria

\begin{tabular}{|l|l|l|l|}
\hline NO. & \multicolumn{1}{|c|}{ Kriteria } & NO. & \multicolumn{1}{|c|}{ Kriteria } \\
\hline 1. & Kebijaksanaan & 6. & Kepemimpinan \\
\hline 2. & Kreatifitas & 7. & Kejujuran \\
\hline 3. & Kecakapan & 8. & $\begin{array}{l}\text { Decision } \\
\text { Making }\end{array}$ \\
\hline 4. & Keaktifan & 9. & Komitmen \\
\hline 5. & Problem Solving & 10. & Tanggung Jawab \\
\hline
\end{tabular}

Berdasarkan kriteria tersebut diberikan rating kecocokan setiap alternatif pada setiap kriteria berupa skala. Untuk skala pada tabel 3 di bawah ini digunakan aturan skala Linkert. 
Tabel 4 Rating Kecocokan Antar Kriteria

\begin{tabular}{|c|c|c|c|}
\hline NO & $\begin{array}{c}\text { ASPEK } \\
\text { PENILAIAN }\end{array}$ & $\begin{array}{c}\text { DATA } \\
\text { AWAL } \\
\end{array}$ & SKALA \\
\hline \multirow{5}{*}{1.} & \multirow{5}{*}{ Kebijaksanaan } & Sangat Baik & 5 \\
\hline & & Baik & 4 \\
\hline & & Cukup Baik & 3 \\
\hline & & Kurang Baik & 2 \\
\hline & & Tidak Baik & 1 \\
\hline \multirow{5}{*}{2.} & \multirow{5}{*}{ Kreatifitas } & Sangat Baik & 5 \\
\hline & & Baik & 4 \\
\hline & & Cukup Baik & 3 \\
\hline & & Kurang Baik & 2 \\
\hline & & Tidak Baik & 1 \\
\hline \multirow{5}{*}{3.} & \multirow{5}{*}{ Kecakapan } & Sangat Baik & 5 \\
\hline & & Baik & 4 \\
\hline & & Cukup Baik & 3 \\
\hline & & Kurang Baik & 2 \\
\hline & & Tidak Baik & 1 \\
\hline
\end{tabular}

\begin{tabular}{|c|c|c|c|}
\hline NO & $\begin{array}{c}\text { ASPEK } \\
\text { PENILAIAN }\end{array}$ & $\begin{array}{l}\text { DATA } \\
\text { AWAL }\end{array}$ & SKALA \\
\hline \multirow{5}{*}{4.} & \multirow{5}{*}{ Keaktifan } & Sangat Baik & 5 \\
\hline & & Baik & 4 \\
\hline & & Cukup Baik & 3 \\
\hline & & Kurang Baik & 2 \\
\hline & & Tidak Baik & 1 \\
\hline \multirow{5}{*}{5.} & \multirow{5}{*}{$\begin{array}{l}\text { Problem } \\
\text { solving }\end{array}$} & Sangat Baik & 5 \\
\hline & & Baik & 4 \\
\hline & & Cukup Baik & 3 \\
\hline & & Kurang Baik & 2 \\
\hline & & Tidak Baik & 1 \\
\hline \multirow{5}{*}{6.} & \multirow{5}{*}{ Kepemimpinan } & Sangat Baik & 5 \\
\hline & & Baik & 4 \\
\hline & & Cukup Baik & 3 \\
\hline & & Kurang Baik & 2 \\
\hline & & Tidak Baik & 1 \\
\hline \multirow{5}{*}{7.} & \multirow{5}{*}{ Kejujuran } & Sangat Baik & 5 \\
\hline & & Baik & 4 \\
\hline & & Cukup Baik & 3 \\
\hline & & Kurang Baik & 2 \\
\hline & & Tidak Baik & 1 \\
\hline
\end{tabular}

\begin{tabular}{|c|c|c|c|}
\hline \multirow{5}{*}{8.} & \multirow{5}{*}{$\begin{array}{l}\text { Decision } \\
\text { making }\end{array}$} & Sangat Baik & 5 \\
\hline & & Baik & 4 \\
\hline & & Cukup Baik & 3 \\
\hline & & Kurang Baik & 2 \\
\hline & & Tidak Baik & 1 \\
\hline \multirow{5}{*}{9.} & \multirow{5}{*}{ Komitmen } & Sangat Baik & 5 \\
\hline & & Baik & 4 \\
\hline & & Cukup Baik & 3 \\
\hline & & Kurang Baik & 2 \\
\hline & & Tidak Baik & 1 \\
\hline \multirow{5}{*}{10.} & \multirow{5}{*}{$\begin{array}{l}\text { Tanggung } \\
\text { jawab }\end{array}$} & Sangat Baik & 5 \\
\hline & & Baik & 4 \\
\hline & & Cukup Baik & 3 \\
\hline & & Kurang Baik & 2 \\
\hline & & Tidak Baik & 1 \\
\hline
\end{tabular}

Sumber: Wawancara pada PT. Makmur Citra Abadi

\section{Metodologi Penelitian}

\subsection{Metode Pengembangan Aplikasi}

Metode penelitian yang digunakan adalah metode prototype. Alur sistem pada tahap prototype adalah sebagai berikut:

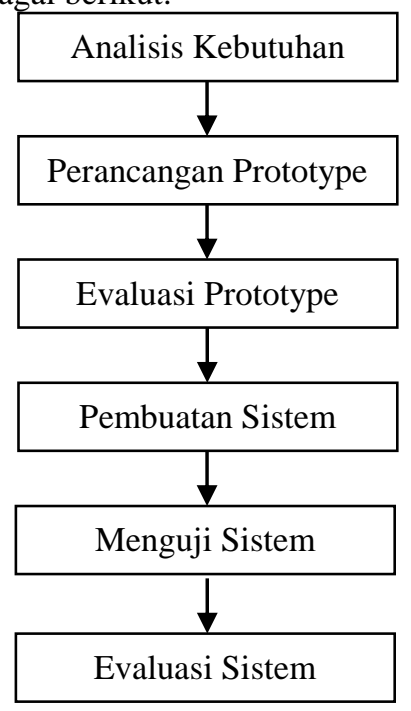

Gambar 1 Alur Sistem Pada Tahap Prototype

\subsection{Metode Pengolahan Data}

Data yang telah didapatkan dari PT. Makmur Citra Abadi selanjutnya akan diolah agar mendapatkan hasil seleksi sesuai dengan kebutuhan perusahaan 


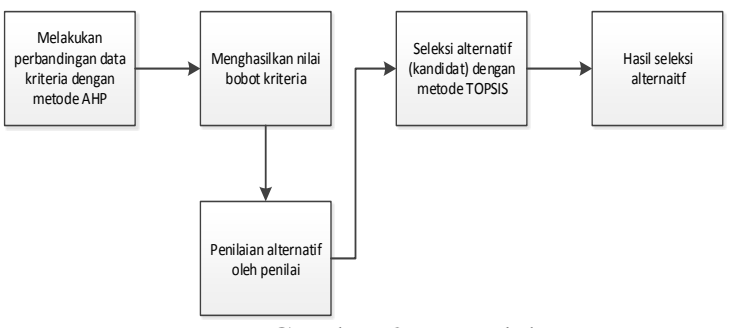

Gambar 2 Pengolahan Data

Pada Gambar 2 dapat dilihat pengolahan data kriteria dilakukan dengan metode AHP untuk menentukan nilai kemudian akan menghasilkan nilai bobot kriteria. Bobot kriteria ini berbeda-beda berdasarkan kebutuhan jabatan dan kebijakan penilai dalam membandingkan kriteria. Setelah itu penilai melakukan penilaian terhadap kandidat dan dilanjutkan seleksi kandidat dengan metode TOPSIS. Hasil seleksi berupa kandidat yang lolos seleksi dengan nilai maksimum hasil metode TOPSIS.

\section{Analisis dan Perancangan Sistem}

\subsection{Rancangan Model Sistem Kenaikan Jabatan}

Rancangan model digunakan untuk membangun sistem kenaikan jabatan yang mampu memberikan penilaian terhadap kandiat untuk menuntukan lolos tidaknya kandidat tersebut.

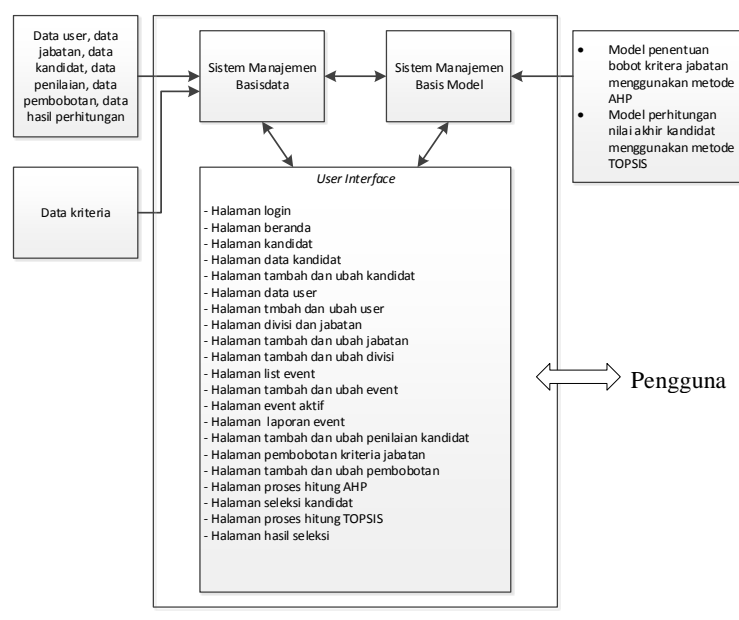

Gambar 3 Model SPK Kenaikan Jabatan

\section{Implementasi dan Pengujian Sistem}

Implementasi dan pengujian dilakukan untuk menguji secara keseluruhan kemampuan dari sistem kenaikan jabatan, implementasi sistem pendukung keputusan ini didasarkan pada hasil yang telah diperoleh dari analisis kebutuhan dan proses perancangan yang dibuat. Pembahasan ini terdiri dari implementasi basis data dan implementasi antarmuka.

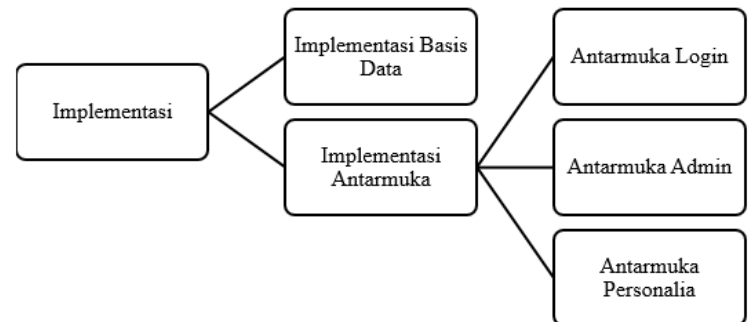

Gambar 4 Alur Pemetaan Implementasi

\section{Hasil Pengujian dan Pembahasan 6.1 Pengujian Hasil}

Hasil perbandingan perhitungan manual dan perhitungan sistem dalam penentuan bobot dapat di lihat dari tabel berikut:

Tabel 5 Hasil Perbandingan Perhitungan Penentuan Bobot AHP

\begin{tabular}{|l|l|c|l|}
\hline No. & Kriteria & $\begin{array}{l}\text { Hasil } \\
\text { Perhitungan } \\
\text { Manual }\end{array}$ & $\begin{array}{l}\text { Hasil } \\
\text { SPK } \\
\text { AHP }\end{array}$ \\
\hline 1. & Kebijaksanaan & 0.14592 & 0.14593 \\
\hline 2. & Kreatifitas & 0.04558 & 0.04568 \\
\hline 3. & Kecakapan & 0.0276 & 0.02761 \\
\hline 4. & Keaktifan & 0.07766 & 0.07764 \\
\hline 5. & Problem Solving & 0.14056 & 0.14067 \\
\hline 6. & Kepemimpinan & 0.03129 & 0.03131 \\
\hline 7. & Kejujuran & 0.04407 & 0.04406 \\
\hline 8. & Decision Making & 0.19196 & 0.19197 \\
\hline 9. & Komitmen & 0.14768 & 0.14768 \\
\hline 10. & Tanggung Jawab & 0.14768 & 0.14768 \\
\hline
\end{tabular}

Hasil perbandingan perhitungan manual dan perhitungan sistem dalam seleksi kandidat dapat dilihat dari tabel berikut:

Tabel 6 Hasil Perbandingan Perhitungan Seleksi Kandidat TOPSIS

\begin{tabular}{|l|l|l|l|}
\hline No. & Nama & $\begin{array}{l}\text { Nilai } \\
\text { Manual }\end{array}$ & Nilai Sistem \\
\hline 1. & Nara & 0.313037 & 0.31273111463286 \\
\hline 2. & Ria & 0.888981 & 0.88990306226768 \\
\hline 3. & Pratama & 0.282071 & 0.28137628053971 \\
\hline 4. & Tyo & 0.718650 & 0.7199225605851 \\
\hline 5. & Gumelar & 0.645209 & 0.64415947860956 \\
\hline
\end{tabular}

\subsection{Pembahasan}

Berdasarkan tabel perbandingan hasil pengujian pada Tabel 5, didapatkan akurasi alternatif kandidat yang naik jabatan antara pengujian perhitungan manual dengan pengujian perhitungan sistem adalah 95\% dan ditunjukkan pada grafik pada Gambar 3 . 


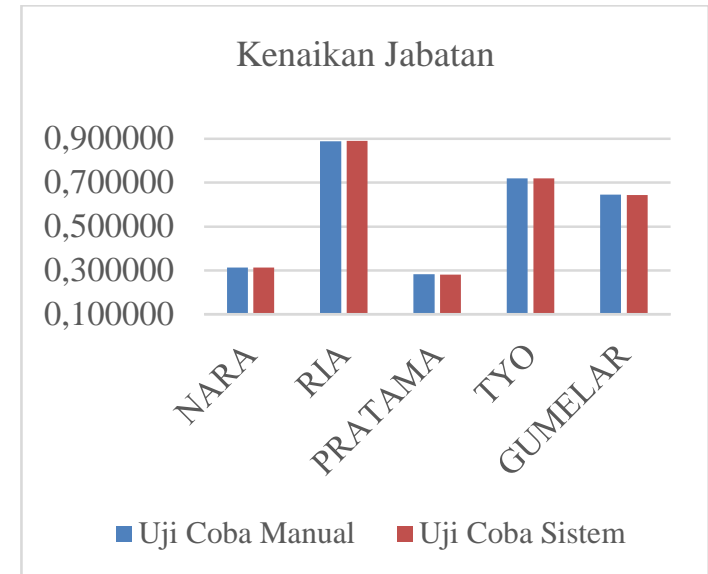

Gambar 3. Grafik Perbandingan Hasil Pengujian

(Sumber: Pengujian \& Pembahasan)

\section{Kesimpulan dan Saran \\ 7.1 Kesimpulan}

Berdasarkan penelitian yang dilaksanakan oleh penulis pada sistem pendukung keputusan kenaikan jabatan dengan metode AHP-TOPSIS, dapat ditarik kesimpulan sebagai berikut:

1. Dengan membandingkan tingkat kepentingan kriteria pada suatu jabatan yang telah dihitung menggunakan metode AHP, maka didapatkan bobot masing-masing kriteria yang konsisten berdasarkan jabatan yang dipilih.

2. Dengan membandingkan nilai alternatif kandidat berdasarkan jabatan yang akan ditempati yang telah dihitung menggunakan metode TOPSIS, maka didapatkan urutan kandidat terbaik yang sesuai dengan kebutuhan dan kemampuan penilai.

3. SPK kenaikan jabatan dengan metode AHPTOPSIS ini telah berhasil dalam membantu penilai dalam memilih kandidat yang terbaik untuk menempati suatu jabatan.

\subsection{Saran}

Saran yang diberikan untuk penegmbangan sistem pendukung keputusan dalam penelitian ini adalah:

1. Dilakukan perbaikan sistem agar menjadi lebih baik seperti menggabungkan metode-metode lain,

2. Dan aplikasi dapat dibuat versi lain, yaitu aplikasi berbasis desktop atau android.

\section{Daftar Pustaka:}

Adriyendi and Yeni Melia. 2013.'DSS Using AHP in Selection of Lecturer". International Journal of Advanced Science and Tecnology Volume 52. Mach. 2013 Hlm. 35-44.

Ariyanto, Rudy. 2013. Sistem Pendukung Keputusan Kelompok Untuk Seleksi Proposal Penelitian Hibah Bersaing Menggunakan Metode FAHP Dan FMCDM (Studi Kasus: UPT P2M
Politeknik Negeri Malang). Universitas Gadjah Mada: Thesis Tidak Diterbitkan.

Asep, dkk. 2012. "Sistem Pendukung Keputusan Penyeleksian Calon Siswa Baru di SMA Negeri 3 Garut". Jurnal Algoritma ISSN 2302-7339 Volume 09 No. 20. Sekolah Tinggi Teknologi Garut.

Ekawati,Aprilia. 2013. Sistem Pendukung Keputusan Pembagian Raskin Dengan Metode Simple Additive Weighting (SAW). Universitas Dian Nuswantoro.

Gunawan, Fandi Halim, Wilson.2014. "Penerapan Metode TOPSIS dan AHP Pada Sistem Penunjang Keputusan Penerimaan Anggota Baru. Studi Kasus: Ikatan Mahasiswa Sistem Informasi STMIK Mikrokil Medan". Jurnal Teknologi Informasi Volume 15 nomor 2, Oktober 2014, ISSN 1412-0100. STMIK Mikrokil Medan.

Kusrini. 2007, Konsep dan Aplikasi Sistem Pendukung Keputusan. Yogyakarta: Andi Offset.

Kusumadewi, S., dkk. 2006. Fuzzy Multi-Attribute Decision Making (Fuzzy MADM). Yogyakarta: Graha Ilmu.

Marimin. 2004. Teknik dan Aplikasi Pengambilan Keputusan Kriteria Majemuk. Jakarta: Grasindo.

Ratih Hafsarah M, Abdul Syukur dan Tyas Catur P., 2010. Penerapan Metode Analytical Hierarchi Process Dalam Penerimaan Karyawan Pada PT. Pasir Besi Indonesia. Jurnal Teknologi Informasi. Volume 6 nomor 1, April 2010, ISSN 1414-9999. Universitas Dian Nuswantoro.

Roger S., Pressman. 2002. Rekayasa Perangkat Lunak Pendekatan Praktisi (Buku Satu). Yogyakarta: ANDI.

Shalehah, Ani. 2014. "Penerapan TOPSIS (Technique for Order Preference by Similarity to Ideal Solution)". Jurnal Statistik Vol 2, No 5. Universitas Brawijaya

Sparague, R. H. and Watson H. J. 1993. Decision Support Systems: Putting Theory Into Practice. Englewood Clifts, N.J., Pretice Hall.

Turban , Efraim \& Aronson, Jay E. 2001. Decision Support Systems and Intelligent Systems. 6th edition. Prentice Hall: Upper Saddle River, NJ.

Turban, E., dkk.. 2005. Decision Support Systems and Intelligent Systems Edisi 7 Jilid 1. Yogyakarta: Andi. 